\title{
Evaluation of the influence of the organizational environment on project cost management based on the Grey Relational Analysis
}

\author{
Zhi Dou,Wenjun Yang \\ College of Civil Engineering, Chang'an University, Xi'an 710061, China
}

\begin{abstract}
Keywords: the Organizational Environment, Engineering Project, Cost Management, Impact Evaluation, Grey Relational Analysis
\end{abstract}

\begin{abstract}
From the organizational environment perspective, to explore the influence factors of project cost management, and to determine a evaluation system about the influence of the organizational environment on project cost management. Using gray system theory to build a model of the gray relational analysis between organizational environment and project cost management. The examples show that this method has a certain theoretical significance and practical value to solve the project cost management.
\end{abstract}

\section{Introduction}

Accompanied by the rapid development of China's construction industry and the further opening up of construction markets, the uncertainty of the external environment which construction enterprises face increased, the underpricing bid between enterprises for contending projects, the drastic fluctuation in raw material prices, the entering barriers are down while the exit cost are still high, the ferocious entering momentum of foreign builders, these make China construction enterprises stand in a competitive industry, and its profit margins are severely squeezed. The way to effectively control the project cost has already become a focus of attention of construction enterprises. Survey shows that the extensive management approach of China's construction enterprises currently has not been fundamentally changed, the corporate structure, operational processes and infrastructure management is weak, the level of project management is low, and the existing project cost should be improved in aspects about management concepts, objectives, means and so on [1].The effective implementation of advanced cost management methods must consider enterprises' particular organizational environment, Kaplan and Norton believes, the advanced cost management and evaluation methods break away from its corresponding organizational environment, the possibility to success almost not exists [2].Therefore, the objective understanding of the organizational environment the construction enterprises face, and the comprehensive analysis about the mechanism of the organizational environment to the project cost management for the construction cost management is essential.

\section{The determination of the affecting factor system of the project cost management by organizational environment}

Organizational environment is a sum of forces and conditions which exist in the internal and external organization and affect the organizational performance. There are many environmental factors in internal and external organization, but not all of these factors constitute the organization's environment, the factors who has no impact on organizational performance do not belong to the environmental factors of organization, and elements of the organizational environment is often in flux, the dynamics of environment perform clearly in a background of fierce competition both in domestic and foreign markets [3].

According to the organization's controllable degree to its faced environment, the organizational environment can be divided into two categories: the internal organizational environment and the external organizational environment. The external environment that construction enterprises face is the sum of various factors which exist around the construction organization and affect the business activities and development of enterprises. The external environmental uncertainty of construction 
enterprises include the general environmental uncertainty and the task environmental uncertainty, the general environmental uncertainty include the uncertainties which brought for construction enterprises from the political environment, economic environment, legal environment and technical environment, and the task environmental uncertainty include the uncertainties which brought for construction enterprises from new entrants, owners, suppliers and existing competitors.

Through the above analysis, the several affecting factors of the project cost management by the organizational environment were researched; this paper considers the factors are: organization structure, control system and social relations. And the table 1, the affecting factor system of the project cost management by organizational environment, is built by these factors.

Tab.1. the Affecting Factor System of the Project Cost Management by Organizational Environment

\begin{tabular}{|c|c|c|}
\hline $\begin{array}{l}\text { First class } \\
\text { index }\end{array}$ & $\begin{array}{l}\text { Second class } \\
\text { index }\end{array}$ & Third class index \\
\hline \multirow{12}{*}{$\begin{array}{c}\text { Project Cost } \\
\text { Management } \\
\qquad A\end{array}$} & \multirow{3}{*}{$\begin{array}{l}\text { Organization } \\
\text { Structure } B_{1}\end{array}$} & Organization Framework $C_{1}$ \\
\hline & & Internal Coordination $C_{2}$ \\
\hline & & Internal Restriction $C_{3}$ \\
\hline & \multirow{7}{*}{$\begin{array}{r}\text { Control } \\
\text { System } B_{2}\end{array}$} & Budget Mechanism $C_{4}$ \\
\hline & & Accounting Mechanism $C_{5}$ \\
\hline & & Monitoring Mechanism $C_{6}$ \\
\hline & & Analyzing Mechanism $C_{7}$ \\
\hline & & Checking Mechanism $C_{8}$ \\
\hline & & Material Cost Management $C_{9}$ \\
\hline & & Project Manager Management $C_{10}$ \\
\hline & \multirow{2}{*}{$\begin{array}{c}\text { Social } \\
\text { Relations } B_{3}\end{array}$} & Major Stakeholder $C_{11}$ \\
\hline & & $\begin{array}{l}\text { External Communication and } \\
\text { Coordination } C_{12}\end{array}$ \\
\hline
\end{tabular}

\section{Evaluation of the influence of the organizational environment on project cost management based on the Grey Relational Analysis}

\section{To determine the weighing values of all levels}

Because of the important degree of the influence of the above indexes on project cost are not identical, it is required to determine the weights. We can choose to invited several experts who adopted the ratio scale method to compare two factors, and to determine the ratio scale between various factors, as shown in table 2 , then in turn collect the statistics of frequency mij of each index ratio scale $\mathrm{Cj}$.

$$
U_{C_{j}}\left(U_{i}\right)=c_{j} \frac{m_{i j}}{n}
$$

In the formula, mij is the number of times of $\mathrm{Ui} \in \mathrm{ci}$; $\mathrm{n}$ is the number of experts to participate in the evaluation; $\mathrm{Uci}(\mathrm{Ui})$ is the ratio scale of $\mathrm{Ui}$ belong to the cj, we can get the ratio scale

$$
R_{i}=\sum_{j=i}^{n} U_{C_{j}}\left(U_{i}\right)
$$


Tab.2. The meaning of the scale

\begin{tabular}{cc}
\hline division & meaning \\
\hline 1 & Have the same importance \\
3 & The former is a bit more important than the latter \\
5 & The former is obviously more important than the \\
latter
\end{tabular}

Calculate the feature vector $\mathrm{W}$ of matrix $\mathrm{H}$, inspect whether have stochastic consistency between matrix $\mathrm{H}$ and the feature vector $\mathrm{W}$, and compute consistency index $\mathrm{CI}=(\lambda \max -\mathrm{n}) /(\mathrm{n}-1)$, when $\mathrm{CR}=\mathrm{CI} / \mathrm{RI}<0.10$, the consistency of judgment matrix is satisfied, or need to adjust the judgment matrix. Among them, the elements $\mathrm{Wi}(\mathrm{i}=1,2, \ldots \mathrm{n})$ of $\mathrm{W}$ represents the lower the weight of each index relative to its upper part index.

\section{Quantitative treatment of indicators}

Evaluation index can be divided into two types: quantitative index and qualitative index. Qualitative indicators are unquantitative fuzzy evaluation index, thus the comprehensive fuzzy evaluation method of quantitative index can be used. By experts fuzzy scoring in the first place, reoccupy the average value to quantify according to the fuzzy membership degree just as is shown in table 3 .

Tab.3. The fuzzy membership list

\begin{tabular}{cccccccc}
\hline fuzzy & best & $\begin{array}{c}\text { bette } \\
\text { language }\end{array}$ & $\begin{array}{c}\text { goo } \\
\text { d }\end{array}$ & $\begin{array}{c}\text { general } \\
\text { ly }\end{array}$ & $\begin{array}{c}\text { ba } \\
\text { d }\end{array}$ & $\begin{array}{c}\text { wors } \\
\text { e }\end{array}$ & $\begin{array}{c}\text { wor } \\
\text { st }\end{array}$ \\
membership & 0.8 & 0.7 & 0.6 & 0.5 & 0. & 0.3 & 0.2 \\
\hline
\end{tabular}

\section{To determine the reference data sequence and compared sequence}

In order to evaluate the eligible object data sequence, the first thing is to determine the evaluation reference data sequence, usually write to $\mathrm{uik}=(\mathrm{ui} 1, \mathrm{ui} 2, \ldots$ uin), $\mathrm{k}=1,2, \ldots \mathrm{s}$.

A comparison with reference data sequence uik have $\mathrm{n}$ data index sequences, and each data sequence (scheme) have s factors (indicators), then these comparative data column can be written as $\mathrm{U} 0=(\mathrm{u} 10, \mathrm{u} 20, \ldots \mathrm{un} 0) \mathrm{T}$.

To determine the reference sequence, according to the comparison reference sequence types of indicators selected, index of different types, different values of the methods. Seen in the literature index types have six kinds, including efficiency, cost, fixed type, range, deviation and deviation interval[4].

\section{Index correlation calculation of index layer}

In order to ensure the quality of modeling and get the right system analysis, the data must be carried out on the original data standardization transformation and data processing, so that the dimension can be eliminated and the data can be comparable. in correlation analysis, the most common methods were used in data transformation are initial value transformation method, the mean transformation method, full transformation method, unitary transformation method, multiple changes, poor maximum transformation method, standardized method and interval value transformation method[4-5]. In this paper, using the standardized method for data processing, namely:

$$
x_{i}^{k}=\left|\frac{u_{i}^{k}}{u_{i}^{0}}\right|, k=1,2, \cdots, s
$$


In the formula, 0 means the reference solution.

Corresponds to a sequence of reference data, there are a number of comparative data sequence, the ith comparative data with reference data sequences in the first $\mathrm{k}$ corresponding indicators of relative difference is the correlation coefficient, can be expressed as

$$
\begin{gathered}
\xi_{i}^{k}=\frac{\min _{i} \min _{k}\left|X_{i}^{k}-X_{i}^{0}\right|+\eta \max _{i} \max _{k}\left|X_{i}^{k}-X_{i}^{0}\right|}{\left|X_{i}^{k}-X_{i}^{0}\right|+\eta \max _{i} \max _{k}\left|X_{i}^{k}-X_{i}^{0}\right|} \\
(i=1,2, \cdots n ; k=1,2, \cdots s)
\end{gathered}
$$

Type: $\eta$ is distinguish coefficient, $0<\eta<1$, typically take $\eta=0.5$.

The weighted average correlation coefficient under various factors

$$
\begin{gathered}
\gamma_{k}=\frac{1}{n} \sum_{k=1}^{n} \omega_{k} \xi_{i}^{k} \\
(i=1,2, \cdots n ; k=1,2, \cdots s)
\end{gathered}
$$

Type: $\omega \mathrm{k}$ is the weight, $0 \leq \omega \mathrm{k} \leq 1$.

According to the comparison and analysis of correlation, multi-level comprehensive evaluation of the construction project cost management is adopted. Generally speaking, the bigger the correlation of engineering project cost management level was, the engineering project cost management situation greater. In this way, we can made a more objective comprehensive evaluation for the construction enterprise project cost management situation, and use this as reference data for the management of engineering project cost.

\section{Example}

Now with the influence of A, B, C three construction enterprise environment present situation on the engineering project cost management as an example to illustrate the specific application of evaluation model of gray association analysis.

The index classification, the classification and the weight of each index of $\mathrm{A}, \mathrm{B}, \mathrm{C}$ three

\begin{tabular}{|c|c|c|c|c|c|c|c|}
\hline \multirow{2}{*}{$\begin{array}{l}\text { Level } \\
\text { indicator } \\
\qquad \mathrm{s}\end{array}$} & \multirow{2}{*}{$\begin{array}{l}\text { The } \\
\text { weigh } \\
\text { t }\end{array}$} & \multirow{2}{*}{$\begin{array}{l}\text { The } \\
\text { second } \\
\text { Level } \\
\text { indicators }\end{array}$} & \multirow[t]{2}{*}{$\begin{array}{l}\text { The } \\
\text { weig } \\
\text { ht }\end{array}$} & \multicolumn{4}{|c|}{$\begin{array}{l}\text { the index sequence of Project } \\
\text { cost } \\
\text { management evaluation }\end{array}$} \\
\hline & & & & $A$ & $B$ & $C$ & $u_{i}^{0}$ \\
\hline \multirow{3}{*}{$B_{1}$} & \multirow{3}{*}{0.3} & $\mathrm{C}_{1}$ & 0.4 & 0.4 & 0.6 & 0.5 & 0.6 \\
\hline & & $\mathrm{C}_{2}$ & 0.3 & 0.5 & 0.7 & 0.6 & 0.7 \\
\hline & & $\mathrm{C}_{3}$ & 0.3 & 0.6 & 0.7 & 0.5 & 0.7 \\
\hline \multirow{7}{*}{$B_{2}$} & \multirow{7}{*}{0.4} & $\mathrm{C}_{4}$ & 0.2 & 0.7 & 0.6 & 0.4 & 0.7 \\
\hline & & $\mathrm{C}_{5}$ & 0.15 & 0.7 & 0.6 & 0.5 & 0.7 \\
\hline & & $\mathrm{C}_{6}$ & 0.1 & 0.6 & 0.5 & 0.5 & 0.6 \\
\hline & & $\mathrm{C}_{7}$ & 0.2 & 0.5 & 0.5 & 0.6 & 0.6 \\
\hline & & $\mathrm{C}_{8}$ & 0.1 & 0.6 & 0.5 & 0.5 & 0.6 \\
\hline & & $\mathrm{C}_{9}$ & 0.12 & 0.6 & 0.6 & 0.7 & 0.7 \\
\hline & & $\mathrm{C}_{10}$ & 0.13 & 0.6 & 0.5 & 0.5 & 0.6 \\
\hline \multirow{2}{*}{$B_{3}$} & \multirow{2}{*}{0.3} & $\mathrm{C}_{11}$ & 0.56 & 0.7 & 0.6 & 0.6 & 0.7 \\
\hline & & $\mathrm{C}_{12}$ & 0.44 & 0.5 & 0.5 & 0.6 & 0.6 \\
\hline
\end{tabular}
construction enterprise organizational environment, are shown in table4 the comprehensive evaluation of engineering project cost management.

Tab.4. The project cost management comprehensive evaluation

Weight is index to describe the affection of properties and various indicators of project cost management evaluation, scored by the expert, calculated the weight according to the type 2.1, 2.2, through the consistency check, in view of the length, not do detailed calculation here.

Determine the optimal index (reference sequence)

According to the principle of determining the optimal index, we can determine the reference sequence $u_{i}^{0}=(0.6,0.7,0.7,0.7,0.7,0.6,0.6,0.6,0.7,0.6,0.7,0.6)$ 


\section{Data standardization process}

By the evaluation index system of project cost management, the evaluation index points belong to three classes. Processed the index sequence standardized according to the type (2.3), three classification subset are obtained. Calculate the absolute difference between the evaluation and the reference sequences sequence matrix, the calculation results are as follows:

$$
\Delta_{\max }^{B_{1}}=0.33, \Delta_{\min }^{B_{1}}=0 ; \Delta_{\max }^{B_{2}}=0.17, \Delta_{\min }^{B_{2}}=0 ; \Delta_{\max }^{B_{3}}=0.43, \Delta_{\min }^{B_{3}}=0 .
$$

\section{Evaluation of the primary engineering project cost management}

Take the resolution $\eta=0.5$, the correlation coefficient of each subset can be calculated according to the type (2.4), and correlation coefficient matrix is established. The table 4 shows that for I indexes, the weights $\omega_{2}^{B_{1}}=(0.4,0.3,0.3)$. According to the type $(2.5)$, he correlation of this indicator can be calculated.

$$
\gamma_{B_{1}}=\omega_{2}^{B_{1}} \cdot \xi^{B_{1}}=\left[\begin{array}{ccc}
0.33 & 0.37 & 0.54 \\
1 & 1 & 1 \\
0.5 & 0.54 & 0.37
\end{array}\right] \cdot\left[\begin{array}{lll}
0.4 & 0.3 & 0.3
\end{array}\right]^{T}=\left[\begin{array}{lll}
0.41 & 1 & 0.47
\end{array}\right]
$$

On the basis of above, the primary evaluation can be conducted. For the class index, the sort of three construction enterprise correlation is $\mathrm{C}>\mathrm{B}>\mathrm{A}$, which the index of engineering project cost management of construction enterprises $\mathrm{B}$ is optimal, $\mathrm{C}$ construction enterprise take the second, $\mathrm{A}$ business is the worst.

Similarly for II indexes, $\gamma_{B_{2}}=\left[\begin{array}{lll}0.79 & 0.35 & 0.5\end{array}\right]$, we can judge that the optimal is A enterprise and B enterprise is the worst. For III indexes,

$\gamma_{B_{3}}=\left[\begin{array}{lll}0.81 & 0.58 & 0.58\end{array}\right]$, we can judge the optimal is A enterprise, B and C enterprise is the same. According to the corresponding evaluation results, management of construction enterprise project cost management is optimized.

\section{The secondary comprehensive evaluation of the gray correlation analysis}

From the primary evaluation,we can be see that in the category of different indicators of the same construction enterprise, both the optimal and the worst index category of engineering project cost management can be appeared. Obviously, it is difficult to reflect the overall condition of the engineering project cost management. Therefore, all categories should be considered to the secondary comprehensive evaluation on engineering project cost management. Primary index weights $\omega 1=(0.3,0.4,0.3)$, according to the type $(2.5)$, we can get comprehensive correlation degree

$$
\gamma=\omega_{1} \cdot \xi^{A}=\left[\begin{array}{ccc}
0.41 & 0.79 & 0.81 \\
1 & 0.35 & 0.58 \\
0.47 & 0.50 & 0.58
\end{array}\right] \cdot\left[\begin{array}{lll}
0.3 & 0.4 & 0.3
\end{array}\right]^{T}=\left[\begin{array}{lll}
0.68 & 0.61 & 0.52
\end{array}\right]
$$

Order By the correlation size: $\gamma_{A}>\gamma_{B}>\gamma_{C}$. As you can see, the construction enterprise project cost management situation of quality for $\mathrm{A}$ is the best, $\mathrm{B}$ enterprise second, $\mathrm{C}$ enterprise is the worst.

\section{Conclusion}

Based on actual engineering project cost management, this paper considers the organizational environment factors and builds the organization environment factors to the engineering project cost management. With gray correlation analysis method to engineering project cost management conducts a multi-level evaluation, obtains different levels of management evaluation results, the result is consistent with the actual situation of construction enterprise.shows that this method has certain theoretical significance and practical value. But in this study, the main factors affecting the project cost management may have failed to be included in some factors, such as enterprise culture, national macro policy and other factors. In future study, we can further complete factors through the design organization environment impact on the engineering project cost of questionnaire. 


\section{References}

[1] XuTang.Based on the strategy of target cost management method in the application of international engineering contracting project .Chong qing.

Southwestern university of finance and economics, 2003:6-7.

[2] Kaplan,Norton.Strategic center type organization. Beijing:Ren min university of China publishing house, 2001.

[3] Yan Haifeng,Wang Ruixu.The modern organization theory and organization innovation.Beijing:People's posts and telecommunications publishing house, 2003:61-81.

[4] Wu Weidong, Jing Guoxun, Wei Jianping. Grey correlation analysis in six coal mine ventilation system scheme (recent) the application of the optimization . Journal of coal , 2001, 34(3): 290-293.

[5] Xiao Xinping, Song Zhongmin,Li Feng. Gray technology base and application.Beijing: Science press.2005. 